\title{
Pan-Africanismo, Negritude e Teatro Experimental do Negro
}

\author{
Kabengele Munanga \\ Universidade de São Paulo (USP), São Paulo, Brasil \\ E-mail:kabe@usp.br
}




\section{Resumo}

Pretende-se neste texto, que integra o conjunto de trabalhos em homenagem ao intelectual negro Guerreiro Ramos, analisar de modo sintético três temas interligados que fizeram parte do pensamento e da linha de ação em busca da libertação do negro. Trata-se do Pan-africanismo, da Negritude e do Teatro Experimental do Negro brasileiro. O primeiro nasceu nos Estados Unidos e nas Antilhas Britânicas, em 1900; o segundo nasceu em Paris, no Quartier Latin por volta de 1935; e o terceiro, no Brasil, em 1944. Apesar de terem nascido em épocas e em espaços geográficos diferentes, os três movimentos convergem como discursos e atitudes intelectuais e políticos em defesa da libertação política do negro da diáspora e do continente africano; do reconhecimento de sua história, de sua cultura, de sua identidade; de sua plena humanidade e de suas contribuições na história da humanidade, assim como nos países das Américas, onde os negros foram deportados e escravizados. Guerreiro Ramos participou da construção do Teatro Experimental do Negro em companhia de Abdias de Nascimento, juntando suas vozes às dos intelectuais negros do Pan-africanismo e da negritude num movimento de ação em busca da inclusão do Negro no Brasil.

Palavras-chave: Pan-africanismo. Negritude. Teatro Experimental. Identidade. Cultura. Liberdade.

\section{Abstract}

I intend in this paper, which is part of the group of works in honor of the black intellectual Guerreiro Ramos, to analyze synthetically three interconnected themes that were part of the thinking and course of action in pursuit of the liberation of black population. It is about the PanAfricanism, from the Negritude and the Brazilian Experimental Theater of the Black. The first was born in the United States and in the British West Indies in 1900; the second was born in Paris, in the Latin Quarter around 1935 and the third in Brazil in 1944. Although they were born in diferente times and geographical areas, the three movements converge as speeches and intellectual and political attitudes in defense of political liberation the black diaspora and the African continent; recognition of their history, their culture, their identity; of their full humanity and its contributions in the history of mankind, as well as in the Americas, where the blacks were deported and enslaved. Guerreiro Ramos participated in the construction of the Black Experimental Theater in Abdias Nascimento company, adding their voices to the black intellectuals of Pan-Africanism and negritude in an action movement, seeking the inclusion of the Black in Brazil.

Keywords:Pan-Africanism. Blackness. Experimental theater. Identity. Culture. Freedom. 
Dan-africanismo, Negritude e Teatro Experimental do Negro são três movimentos diaspórico-africanos que nasceram em épocas e contextos históricos diferentes, porém têm algumas convergências em termos político-ideológicos e linhas de ação que pretende-se demonstrar no exercício da presente comunicação. No entanto, um breve histórico de cada um se faz necessário antes de especular sobre suas linhas de divergência e convergência. Cronologicamente começarei minha divagação pelo mais antigo, ou seja, o pan-africanismo e terminarei pelo mais recente, o teatro experimental do negro.

O pan-africanismo nasceu no início do século XX entre os negros de língua inglesa, particularmente dos Estados Unidos e das Antilhas Britânicas. A primeira conferência pan-africana foi organizada em Londres em 1900 por um advogado de Trinidad, Henry S. Williams. Depois da primeira Guerra Mundial, ela se amplificou sob a iniciativa de Georges Padmore e W. E. B. Dubois. Em sua ótica, a luta de um povo para sua independência nacional reforçava a luta dos outros e viceversa e era reforçada pela luta desses outros. Ou seja, o regime colonial deveria ser combatido em conjunto e não isoladamente. A negritude, posição intelectual e o pan-africanismo, posição política, convergiam ao afirmar respectivamente que todos os africanos tinham uma civilização comum e que todos os africanos deviam lutar juntos. Nesse sentido, o movimento da negritude e o movimento do pan-africanismo pertencem à africanidade no plano da ação (Maquet, 1967, p. 7-15)

A questão que se colocava na literatura americana antes do movimento pan-africanista era saber se os negros dos Estados Unidos tinham preservado alguma coisa da herança africana. Mais grave do que isso, colocaram em dúvida a identidade cultural das minorias negras americanas ao fazer delas coletividades sem passado ou envergonhadas 
de suas origens africanas. Comparados aos outros grupos étnicos que compõem a população americana, os negros apareciam desprovidos de um patrimônio cultural próprio, porque seus antepassados trazidos da África chegaram "nus", sem poder carregar nada com eles, até porque eram "oriundos de um continente povoado de tribos selvagens e sanguinárias". Embora os especialistas considerassem com reserva e nuanças essa visão simples, o conjunto dos americanos brancos a considerava evidente. Aceitavam que seus compatriotas negros, pelo fato de não possuírem nenhuma bagagem cultural legada por seus ancestrais, não tinham consequentemente um passado criador de valores. Os escravizados eram evidentemente descendentes de inúmeras gerações africanas, mas como no mundo animal essas gerações só transmitiram o único bem preciso: a vida. O "resto", isto é, as técnicas de produção dos bens, as organizações sociais como a família, as crenças religiosas e mágicas, etc. era pobre, rudimentar, viciado e sem progresso. Essas "hordas e tribos" viviam fora do circuito da história que produziu pouco a pouco as brilhantes civilizações cujas aquisições foram se enriquecendo na medida em que passava o tempo. Os negros americanos não tinham o passado africano e o que eles transmitiam para seus filhos era: a língua inglesa, a religião cristã, a polidez que convém aos domésticos das grandes fazendas do Sul, tudo isso foi aprendido dos brancos (Herskovits, 1962, p. 58-78).

Após séculos de imitação cega, alguns escritores negros tomaram consciências de que, de todos os grupos étnicos povoando os Estados Unidos - anglo-saxões, italianos, alemães, poloneses, judeus, etc. eles são os únicos a sofrer uma lavagem cerebral. Levando-os até a acreditar que são naturalmente inferiores e não têm história. Mas essa visão alienante foi interrompida pelo Movimento Pan-Africanista cujos escritores preocupavam-se em estabelecer a verdade e exorcizar entre seus irmãos de raça os sentimentos de profunda rejeição inculcados durante séculos. Limitemo-nos apenas aos dois mais conhecidos: O Dr. Du Bois e Langston Hughes, respectivamente considerados como pai da negritude e representante do movimento conhecido como de Renascimento Negro. 
W. E. D. Du Bois (nascido em 1863) fez seus estudos nas Universidades de Fuk, Harvard e Berlin, onde se doutorou em Filosofia. Seus trabalhos como historiadores revelaram aos companheiros negros um passado africano do qual eles não devem se envergonhar:

Sou negro e me glorifico deste nome; sou orgulhoso do sangue negro que corre em minhas veias. Declarou ele, sem hesitação (Du Bois, 1977, p. 14 apud MUNANGA, 2009, p. 46). Em 1900, foi secretário do Primeiro Congresso Pan-Africano, convocado em Londres por um advogado de Trindade, Henry Sylvester Williams, movimento do qual se tornou presidente depois da morte deste último. É considerado o pai do pan-africanismo contemporânea que antes dos africanos, protestou contra a política imperialista na África, em favor da independência, na perspectiva de uma associação de todos os territórios para defender e promover sua integridade. Sem pregar a volta para África dos negros americanos, defendia os direitos deles enquanto cidadãos da América e exortava os africanos a se libertarem em sua própria terra. Por ter defendido também a volta às origens, Du Bois merece também o nome de Pai da Negritude. (Munanga, 2012, p. 30-45, grifo do autor)

Sua influência foi considerável sobre personalidades africanas de primeiro plano, como Asikiwe Nandi, primeiro presidente da Nigéria, Kwame N'Krumah, primeiro presidente da República de Gana, cujo defesa do pan-africanismo foi uma de suas ideias-forças; Jomo Kenyata, primeiro presidente da República do Quênia (Munanga, 2012, p. 46)

Du Bois exercerá também profunda ascendência sobre os escritores negros americanos. Seu livro Almas negras tornou-se uma verdadeira bíblia para os intelectuais do movimento Renascimento Negro (entre 1920 e 1940). Reagindo, por sua vez, contra os estereótipos e preconceitos inveterados que circulavam a respeito do negro, longe de lamentar-se de sua cor, como acontecia com alguns no passado, o movimento reivindica-a, encontrando nela fonte de glória. Tratava-se de ter a liberdade de se expressar como se é, e sempre se foi; de defender o direito ao emprego, ao amor, à igualdade, ao respeito; de assumir a cultura, o passado de sofrimento. A origem africana. 
Todo esse programa é revelado de forma concisa e sem arrogância num parágrafo célebre de um artigo da revista The Nation, de 23 de junho de 1926 (apud Munanga, 2009, p. 47), considerado o manifesto do movimento ou, ainda, a declaração de independência do artista negro:

Nós, criadores da nova geração negra, queremos exprimir nossa personalidade sem vergonha nem medo. Se isso agrada aos brancos, ficamos felizes. Se não, pouco importa. Sabemos que somos bonitos. E feios também. O tantã chora, o tantã ri. Se isso agrada à gente de cor, ficamos muitos felizes. Se não, tanto faz. É para o amanhã que construímos nossos sólidos templos, pois sabemos edificá-los, e estamos erguidos no topo da montanha, livres dentro de nós.

Langston Hughes (nascido em 1902, de pai branco e mãe negra) foi também muito prestigiado pelos iniciadores da Negritude. Quando foi a Paris, tornou-se amigo pessoal de Leon Damas e de Senghor. Não à vontade na civilização ocidental, segundo ele, dura, forte e fria, seu coração bate nos tantãs africanos e contempla a sarabanda das luas selvagens. "Todos os tantãs do mato batem no meu sangue. Toda as luas selvagens e ferventes do mato brilham na mina alma" (Munanga, 2009, p. 47).

No entanto, ele não procurou fugir do combate cotidiano do seu povo. É na América que ele ficará, pois escreverá: Eu também sou a América.

A Negritude, filha do pan-africanismo, nasce nas décadas de 1930 no "quartier Latim", em Paris, entre os estudantes negros da diáspora, especificamente das Antilhas franceses e da África colonizada. Quando esses estudantes começaram a povoar as universidades francesas, logo começaram a perceber pouco a pouco, as flagrantes contradições entre as políticas de assimilação. O mito da civilização ocidental como modelo absoluto, tal como lhes era ensinado nas colônias, começou a se desfazer.

Estávamos orgulhosos de sermos franceses, apesar de negros africanos, declarou Senghor: Revoltamo-nos, às vezes, por sermos considerados apenas consumidores de civilizações. As contradições da Europa: a ideia não ligada ao ato, a palavra ao gesto, a razão ao coração e 
daí à arte. Estávamos preparados para gritar: hipocrisia! (Munanga, 2009, p. 48)

As circunstâncias em que o conteúdo da negritude foi elaborado nos meios intelectuais negros de Paris por volta de 1935 são essenciais para sua compreensão. Naqueles tempos em que a colonização de conquista terminava e a Europa começava a instalar-se tranquilamente na África para ali ficar indefinitivamente, os estudantes negros duvidavam ainda de suas próprias culturas. Os coloniais exportavam na África a civilização ocidental. Mas para o uso dos africanos essa civilização era filtrada e censurada, porque tudo que vinha da Europa não convinha para essas crianças grandes que eram os negros e para que eles pudessem respeitar os brancos achava-se melhor não deixá-los ver certas coisas. Aos olhares dos coloniais, a civilização europeia, simplesmente chamada civilização, estava para se estabelecer numa espécie de deserto cultural. O direito europeu não encontrava outro direito, mas sim costumes bárbaros; o casamento monogâmico não se substituía a uma outra forma de casamento, mas sim a uma concubinagem imoral; as religiões cristãs não se opunham a outras religiões, mas sim às superstições ridículas (Adotevi, 1972, p. 118-121).

A potência material branca que se difundia na Europa e na África, a pressão psicológica considerável exercida pela administração colonial e pelos missionários abalaram profundamente a visão que certos africanos tinham de suas heranças sociais e culturais. Eles as julgaram do ponto de vista europeu e as consideravam inferiores e vergonhosas (Munanga, 1986). Para se curar desse sofrimento, muitos intelectuais tornaram-se assimilados, isto é: ocidentais de pele negra (Fanon, 2008). Mas como eles tinham justamente a pele negra, esta fazia da assimilação plenamente alcançada no plano cultural um engano no plano da vida social. O médico negro continuava a ser tratado por "tu" por um lojista branco.

A negritude é um conceito de síntese. Mas, antes de tudo, ela é uma atitude total de resposta a uma situação. Aimé Césaire, com Léopold Sedar Senghor, Léon Damas e outros, cria o termo negritude e o define como "consciência de ser negro, simples reconhecimento de um fato que implica aceitação - assumir sua negritude, sua história e sua 
cultura". E Senhor escreve: "É antes de mais nada uma negação, mais precisamente a afirmação de uma negação". É o momento necessário de um movimento histórico: o recuso de assimilar-se, de se perder no outro. Mas como este movimento é histórico, ele é ao mesmo tempo dialético, pois a recusa do outro é a afirmação de si. Essa afirmação de si diante da civilização ocidental conduziu esses intelectuais negros vivendo na Europa a tomar consciência de uma civilização africana, apesar das diferenças entre suas diversas heranças sociais. Assim, o conceito de negritude transcende as particularidades étnicas e nacionais. É, segundo as palavras de Senghor, “o patrimônio cultural, os valores e, sobretudo o espírito da civilização negro-africana".

A negritude criticava a relação de dependência cultural que o colonizador tentava restabelecer e dava fundamento à luta para a reconquista da independência africana.

O exame da produção discursiva dos escritores da negritude permite levantar três objetivos principais: buscar o desafio cultural do mundo negro (a identidade negra africana), protestar contra a ordem colonial, lutar pela emancipação de seus povos oprimidos e lançar o apelo de uma revisão das relações entre os povos para que se chegasse a uma civilização não universal como a extensão de uma regional imposta pela força - mas uma civilização do universal, encontro de todas as outras, concretas e particulares. Entre os três desafios que acabamos de levantar, o que impressiona imediatamente por sua amplitude e pela variedade das disciplinas mobilizadas à sua compreensão é a afirmação e a reabilitação da identidade cultural, da personalidade própria dos povos negros. Poetas, romancistas, etnólogos, filósofos, historiadores, etc. quiseram restituir à África o orgulho do seu passado, afirmar o valor de suas culturas, rejeitar uma assimilação que teria sufocado a sua personalidade. Por Césaire, a negritude é o simples reconhecimento do fato de ser negro, a aceitação de seu destino, de sua história e de sua cultura. Mais tarde, Césaire a definiu em três palavras: identidade, fidelidade, solidariedade. A identidade consiste em assumir plenamente, com orgulho, a condição de negro, em dizer, cabeça erguida: sou negro. A palavra foi despojada de tudo o que carregou no passado, como desprezo, transformando este último numa fonte de orgulho 
para o negro. A fidelidade repousa numa ligação com a terra-mãe, cuja herança deve, custe o que custar, demandar prioridade. A solidariedade é o sentimento que nos liga secretamente a todos os irmãos negros do mundo. Césaire rejeita todas as máscaras brancas que o negro usava e faziam dele uma personalidade emprestada (Munanga, 2009).

O Teatro Experimental do Negro (TEN) foi fundado em 1944 na liderança de Abdias de Nascimento com a participação do intelectual Guerreiro Ramos. Apesar das denúncias e da luta da Frente Negra Brasileira, naquela época a discriminação racial reinava absoluta. No teatro brasileiro, conta Abdias, o negro não entrava nem para assistir espetáculo e muito menos para atuar no palco. Ele só entrava no teatro vazio para limpar a sujeira deixada pelo elenco e pela plateia, exclusivamente composta de brancos. O Teatro Experimental Negro nasceu para contestar essa discriminação, formar atores e dramaturgos negros, e resgatar uma tradição cultural cujo valor foi sempre negado ou relegado aos ridículos padrões culturais brasileiros: a herança africana em sua expressão brasileira, ou seja, a africanidade brasileira. Assim, o TEN continuava a tradição de protesto legada pela Frente Negra, não no sentido de assimilação, mas integrava a essa dimensão a reivindicação da diferença, ou seja, reivindicava o reconhecimento do valor civilizatório da herança africana e da personalidade afro-brasileira. Assumia e trabalhava sua identidade específica, exigindo para que a diferenças deixasse de ser degradada em desigualdade. Essa dupla dimensão do TEN é claramente explicitada na seguinte frase atribuída ao seu idealizador fundador, Abdias de Nascimento:

Fundando o Teatro Experimental do Negro em 1944, pretendi organizar um tipo de ação que a um tempo tivesse significado cultural, valor artístico e função social [...]. De início, havia a necessidade do resgate da cultura negra e seus valores violentados, negados, oprimidos e desfigurados [...]. O negro não desejava ajuda isolada e paternalista, como um favor especial. Ele deseja e reclama um status elevado na sociedade, na forma de oportunidade coletiva para todos, a um povo com irrevogáveis direitos históricos [...] a abertura de oportunidades reais de ascensão econômica, política, cultural, social, para o negro, respeitando-se sua origem africana (Abdias apud Guimarães; Hunteley, 2000, p. 206-210) 
Diz Abdias que ele concebeu o TEN durante uma viagem em Lima, no Peru, quando assistia à peça O Imperador Jones. De Eugene O ${ }^{\prime}$ Neil, estrelada por Hugo D’Evieiri, um argentino branco pintado de preto. Refleti: no Brasil fatalmente acontece o mesmo. Em primeiro lugar, no teatro não existia uma peça com protagonista negro de densidade dramática; só estereótipo do moleque bobo de riso fácil, a mãe preta abnegada ou o pai João submisso. Talvez uma peça norte-americana com protagonista negro até se poderia montar, mas um autor negro no papel principal, nunca. Sempre cultura discriminatória exigiria o pixe, pois no seu conceito, um ser inferior não seria capaz de desempenhar um papel de tal envergadura.

De volta ao Brasil, consegui reunir um grupo pequeno de resolutos e de convictos para iniciar os trabalhos do Teatro Experimental do Negro, então, resolvemos estrear com uma produção do mesmo o Imperador Jones. Unanimemente, todos aconselharam uma estreia mais modesta, uma peça que não exigisse tanto empenho, expressão dramática e sofisticação de elenco de novatos, ainda por cima negros!

Em seguida, ele mostra reações muito diferentes. Na África, no plano intelectual e artístico e no plano político, há a tomada da consciência do passado africano, a reivindicação da africanidade e da independência. É o movimento da Negritude que começou por volta de 1935 no meio de estudantes africanos em Paris; é o processo de descolonização que começa em 1956 (República do Sudão) e 1957 (Gana) e atingiu seu apogeu em 1960 (27 independências). Nos Estados Unidos é a luta para o reconhecimento da igualdade jurídica no Sul, da igualdade social no Norte, e por toda parte contra o obstáculo econômico que representa a cor da pele. Parece que os negros americanos naquela época, salvo alguns grupos como o Black Muslims ou o Black Power, reclamavam a integração a mais completa na sociedade americana. Mais do que a africanidade, eles preferiam a americanidade.

Os negros africanos, embora formassem uma minoria sociológica nas colônias, representavam uma considerável maioria demográfica enquanto os negros americanos representavam uma minoria ao mesmo tempo sociológica e demográfica. No Sul do Saara, a situação dos contatos entre brancos e colonizados foi comparativamente curta, se- 
tenta e cinco anos em média; nas Américas ela durou muitos séculos. $\mathrm{Na}$ África, a força econômica e social das castas coloniais brancas foi relativamente menos considerável que a exercida pelas comunidades brancas nos Estados Unidos. Em muitos domínios da vida coletiva africana, as instituições e as normas tradicionais permaneceram dominantes durante todo o período colonial (por exmeplo, organizações familiais, técnicas de agricultura, de caça e criação de gado, línguas, crenças religiosas, etc.), enquanto nos Estados Unidos os africanismos foram menos numerosos, comparativamente ao Brasil, que recebeu cerca de $40 \%$ de todos os africanos deportados nas Américas.

Evoca-se frequentemente a desintegração das culturas africanas sob as influências que não existiam na África pré-colonial: os livros, as técnicas industriais, as administrações complexas, as intensas relações internacionais. $\mathrm{O}$ fato de que os fragmentos culturais africanos trazidos no Novo Mundo pelos escravizados tenham permitido às comunidades negras das Américas reconstruir em parte o tecido original e mantê-lo é uma prova de extraordinária resistência da africanidade na diáspora.

Evidentemente, as sociedades africanas de hoje não vivem da mesma herança cultural do fim do século XIX quando começou a colonização. Mas qual é a comunidade cultural que possui hoje o patrimônio cultural de antigamente? Todas as civilizações se enriqueceram incrivelmente em contato umas com as outras. No entanto, elas não perderam sua identidade, que se enraíza em seu passado (Thomas, 1982, p. 304).

Africanidades brasileiras (plural), na minha interpretação, poderia ter o mesmo sentido que os africanismos de Herskovits para designar os elementos da herança africana que sobreviveu na diáspora. Todas as comunidades de matrizes africanas na diáspora reivindicam hoje duas coisas complementares: a inclusão nas sociedades que escravizaram seus antepassados africanos e seus descendentes não no sentido assimilacionista, mas reconhecendo ao mesmo tempo sua identidade ancorada por um lado na continuidade africana, daí a importância de ensinar a história e a cultura africana e, por outro lado, nas culturas de resistência que elas criaram no novo mundo em defesa de sua dignidade e liberdade humanas, daí a importância de ensinar também 
a história e a cultura negra na diáspora. A nova equação é: queremos ser incluídos sim, mas reconhecendo e respeitando ao mesmo tempo nossa identidade que passa pelas nossas diferenças corporais, culturais e históricas. Não é sem fundamento que os negros americanos rejeitaram politicamente a identidade de afro-americanos (Afro-Americans) que corresponderia à nossa de afro-brasileiros, para adotar a identidade de africanos americanos (Africans Americans), para reafirmar sua herança africana que por muito tempo lhes foi negada.

Na esfera da ação, a unidade africana foi também reconhecida no plano intelectual pelo movimento da negritude e na ação política pelo movimento do pan-africanismo. As circunstâncias em que o conteúdo da negritude foi elaborado nos meios intelectuais negros de Paris por volta de 1935 são essenciais para sua compreensão. Naqueles tempos em que a colonização de conquista terminava e a Europa começava a instalar-se tranquilamente na África para ali ficar indefinitivamente, os estudantes negros duvidavam ainda de suas próprias culturas. Os coloniais exportavam na África a civilização ocidental. Mas para o uso dos africanos essa civilização era filtrada e censurada, porque tudo que vinha da Europa não convinha para essas crianças grandes que eram os negros e para que eles pudessem respeitar os brancos achava-se melhor não deixá-los ver certas coisas. Aos olhares dos coloniais, a civilização europeia, simplesmente chamada civilização, estava para se estabelecer numa espécie de deserto cultural. O direito europeu não encontrava outro direito, mas sim costumes bárbaros; o casamento monogâmico não se substituía a uma outra forma de casamento, mas sim a uma concubinagem imoral; as religiões cristãs não se opunham a outras religiões, mas sim às superstições ridículas.

A potência material branca que se difundia na Europa e na África, a pressão psicológica considerável exercida pela administração colonial e pelos missionários abalaram profundamente a visão que certos africanos tinham de suas heranças sociais e culturais. Eles as julgaram do ponto de vista europeu e as consideravam inferiores e vergonhosas (Munanga, 1986). Para se curar desse sofrimento, muitos intelectuais tornaram-se assimilados, isto é: ocidentais de pele negra. Mas como eles tinham justamente a pele negra, esta fazia da assimi- 
lação plenamente alcançada no plano cultural um engano no plano da vida social. O médico negro continuava a ser tratado por "tu" por um lojista branco.

A negritude é um conceito de síntese. Mas, antes de tudo, ela é uma atitude total de resposta a uma situação. Aimé Césaire, com Léopold Sedar Senghor, Léon Damas e outros, cria o termo negritude e o define como "consciência de ser negro, simples reconhecimento de um fato que implica aceitação - assumir sua negritude, sua história e sua cultura". E Senghor escreve: "É antes de mais nada uma negação, mais precisamente a afirmação de uma negação". É o momento necessário de um movimento histórico: o recuso de assimilar-se, de se perder no outro. Mas como este movimento é histórico, ele é ao mesmo tempo dialético, pois a recusa do outro é a afirmação de si. Essa afirmação de si diante da civilização ocidental conduziu esses intelectuais negros vivendo na Europa a tomar consciência de uma civilização africana, apesar das diferenças entre suas diversas heranças sociais. Assim, o conceito de negritude transcende as particularidades étnicas e nacionais. É, segundo as palavras de Senghor, "[...] o patrimônio cultural, os valores e, sobretudo o espírito da civilização negro-africana." (Munanga, 1986, p. 53).

A negritude justificava a relação de dependência cultural que o colonizador tentava restabelecer e dava fundamento à luta para a reconquista da independência africana. Arma ideológica, a negritude reencontra outro movimento anterior de origem diferente (disporia), o pan-africanismo. Movimento que nasceu no início do século XX entre os negros de língua inglesa, particularmente dos Estados Unidos e das Antilhas Britânicas. A primeira conferência pan-africana foi organizada em Londres, em 1900, por um advogado de Trinidad, Henry S. Williams. Depois da primeira Guerra Mundial, ela se amplificou sob a iniciativa de Georges Padre e W.E.B. Dúbios. Em sua ótica, a luta de um povo para sua independência nacional reforçava a luta dos outros e vice-versa e era reforçada pela luta desses outros. Ou seja, o regime colonial deveria ser combatido em conjunto e não isoladamente. A negritude, posição intelectual e o pan-africanismo, posição política, convergiam ao afirmar respectivamente que todos os africanos tinham uma civilização comum e que todos os africanos deviam lutar 
juntos. Neste sentido, o movimento da negritude e o movimento do pan-africanismo pertencem à africanidade no plano da ação (Maquet, 1967, p. 14-15).

\section{Referências}

ADOTEVI, Stanilslas. Négritude et négrologues. Paris: Union générale d'éditions, 1972.

FANON, Franz. Pele negras máscaras brancas. Salvador: EDUFBA, 2008.

HERSKOVITS, J. Melville. L’Héritage du Noir. Paris: Présence Africaine, 1962.

MAQUET, Jacques. Africanité Traditionnelle et Moderne. Paris: Présence Africaine, 1967.

MUNANGA, Kabengele. Negritude: usos e sentidos. 3. ed. Belo Horizonte: Autêntica, 2009.

. O conceito de africanidade nos contextos africano e brasileiro. In:

OLIVEIRA, Jurema (Org.). Africanidades e Brasilidades: culturas e territorialidades. Rio de Janeiro: Dialogart, 2015. p. 9-25.

NASCIMENTO, Abdias do; NASCIMENTO, Elisa Larkin. Reflexões sobre o Movimento Negro no Brasil, 1938-1997. In: GUIMARÃES, Antônio Sergio Alfredo; HUNTLEY, Lynn (Org.). Tirando a máscara: ensaios sobre o racismo no Brasil. São Paulo: Paz e Terra, 2000. p. 203-235.

THOMAS, L.Vincent. Les idéologies negro-africaines d'aujourd'hui. Paris: Librairie A. G. Nizet, 1982. 